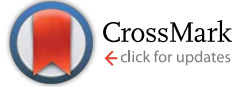

Cite this: RSC Adv., 2015, 5, 12530

Received 24th October 2014 Accepted 12th January 2015

DOI: $10.1039 / c 4 r a 13084 g$

www.rsc.org/advances

\section{The $\mathrm{Zn}$-vacancy related green luminescence and donor-acceptor pair emission in $\mathrm{ZnO}$ grown by pulsed laser deposition}

\author{
Zilan Wang, ${ }^{a}$ S. C. Su, ${ }^{a}$ M. Younas, ${ }^{a}$ F. C. C. Ling, ${ }^{\text {*a }}$ W. Anwand ${ }^{\mathrm{b}}$ and A. Wagner ${ }^{\mathrm{b}}$ \\ A low temperature $(10 \mathrm{~K})$ photoluminescence study shows that green luminescence (GL) peaking at $2.47 \mathrm{eV}$ \\ and near band edge (NBE) emission at $3.23 \mathrm{eV}$ are introduced in undoped $\mathrm{ZnO}$ grown by pulsed laser \\ deposition (PLD) after $900{ }^{\circ} \mathrm{C}$ annealing. The NBE emission exhibiting blue shift with increasing \\ temperature is assigned to the transitions of the donor-acceptor-pair (DAP)/free-electron-to-acceptor \\ (FA). Positron annihilation spectroscopy (PAS) study shows that the introduction of the GL is correlated \\ with the formation of the $\mathrm{Zn}$ vacancy-related defect $\left(\mathrm{V}_{\mathrm{Zn}}\right)$. Comparing the transition energies of $\mathrm{V}_{\mathrm{Zn}}$ \\ obtained by the previous first principles calculation [Janotti and Van de Walle, Phys. Rev. B: Condens. \\ Matter Mater. Phys., 2007, 76, 165202], the GL is associated with the transition from the conduction \\ band to the $\varepsilon(-/ 2-)$ state of $V_{Z n}$ and the DAP/FA emission involves the acceptor level $\varepsilon(0 /-)$ of $V_{Z n}$.
}

\section{Introduction}

$\mathrm{ZnO}$ has attracted extensive attention as a potential material for a variety of device applications, including optoelectronics operating in the wavelength range of ultra-violet (UV), solidstate white lighting, and sensors. ${ }^{1,2}$ Based on the ZnO-related structures, UV light emitting diode (LED) fabrication and low threshold UV lasing have been achieved. ${ }^{3-8}$ However, the realization of practical $\mathrm{ZnO}$-based optoelectronic devices is still hindered by the asymmetric p-type doping difficulty. ${ }^{1,2}$ Results of recent p-type doping studies suggest that more exact and detailed knowledge concerning the physics of the defects and the corresponding control is needed to achieve reliable p-type doping in $\mathrm{ZnO}$. However, the understanding of defects in $\mathrm{ZnO}$ is far from complete and controversial.

One of the controversial assignments of defect spectroscopic signal in $\mathrm{ZnO}$ is the green luminescence (GL). GL is a broad defect emission peaking at 2.3-2.5 eV, which has been associated with $\mathrm{Cu}$-impurity, ${ }^{9} \mathrm{Zn}$-vacancy, ${ }^{10-13} \mathrm{O}$-vacancies, ${ }^{14-16} \mathrm{Zn}_{\mathrm{i}^{-}}$ related complexes, ${ }^{17}$ and oxide antisite defects. ${ }^{18}$ It is generally accepted that the GL with the fine structure is originated from the $\mathrm{Cu}$ impurity and the structureless GL is associated to the intrinsic defects. Ton-That et al. ${ }^{19}$ identified two kinds of GL's having peak positions at $2.30 \mathrm{eV}$ and $2.53 \mathrm{eV}$ respectively in the $\mathrm{O}$-rich and $\mathrm{Zn}$-rich $\mathrm{ZnO}$ samples, and they are respectively assigned to $\mathrm{V}_{\mathrm{Zn}}$ and $\mathrm{V}_{\mathrm{O}}$. $\mathrm{Lv}$ and $\mathrm{Li}^{20}$ show that the peak positions and shapes of the GL's observed in their $\mathrm{ZnO}$ powder samples

${ }^{a}$ Department of Physics, The University of Hong Kong, Pokfulam Road, Hong Kong, $P$. R. China. E-mail: ccling@hku.hk

${ }^{b}$ Institute of Radiation Physics, Helmholtz-Zentrum Dresden-Rossendorf, Bautzner Landstr. 400, 01328 Dresden, Germany depend on the abundance of the $\mathrm{V}_{\mathrm{O}}, \mathrm{V}_{\mathrm{Zn}}$ and $\mathrm{O}_{\mathrm{i}}$ defects. These recent results show that there are more than one origins of GL's associated with the different intrinsic defects in ZnO. Donoracceptor pair (DAP) emission at $3.220 \mathrm{eV}$ has been observed in undoped $\mathrm{ZnO}$ at the temperature of $5 \mathrm{~K}^{21}$ As temperature increases, the $3.220 \mathrm{eV}$ emission quenches and the $3.236 \mathrm{eV}$ free electron to acceptor (FA) emission emerges because of the thermal ionization of the shallow donors. The acceptor level was found to be $195 \pm 10 \mathrm{meV}$ and the acceptor was attributed to $\mathrm{N}_{\mathrm{O}}$.

In the present study, undoped ZnO films are grown on sapphire by pulsed laser deposition (PLD) with different substrate temperatures and oxygen pressures. Low temperature PL study shows that after annealing at $900{ }^{\circ} \mathrm{C}$, the GL (peaking at $2.47 \mathrm{eV}$ ) originated from a single type of defect and the near band emission $(3.23 \mathrm{eV})$ are created. Positron annihilation spectroscopy (PAS) is employed to reveal the origin of the emissions. The origins of the emissions will also be discussed by making comparison to the previous results of first principle calculations.

\section{Experimental}

Undoped ZnO films with thickness of $300 \mathrm{~nm}$ were grown on the $c$-plane sapphire using the method of PLD. To carry out a systematic study and to obtain a conclusive result, films are grown with different substrate temperatures $\left(T_{\text {sub }}=300{ }^{\circ} \mathrm{C}\right.$ and $\left.600^{\circ} \mathrm{C}\right)$ and oxygen pressures $\left(P\left(\mathrm{O}_{2}\right)=0 \mathrm{~Pa}, 1.3 \mathrm{~Pa}\right.$ and $\left.5 \mathrm{~Pa}\right)$. The ZnO target (99.999\% impurity) is obtained from Kurt J. Lesker Co. The background pressure for the growth is $10^{-4} \mathrm{~Pa}$. The $248 \mathrm{~nm}$ laser pulse having the pulse energy of $300 \mathrm{~mJ}$ and repetition rate of $2 \mathrm{~Hz}$ from the Coherent COMPexPro 102 excimer laser is used for the PLD growth. Isochronal post- 
growth annealing was carried out at different temperatures with the period of 40 minutes in Ar atmosphere. Another piece of ZnO sample was placed on top of the sample being studied during the annealing in order to prevent the surface damage during the annealing process. The samples thus fabricated have been systematically and comprehensively characterized by a variety of spectroscopies including Atomic force microscopy (AFM), X-ray diffraction (XRD), secondary ion mass spectroscopy (SIMS), Hall measurement, Raman spectroscopy, and PAS. The details of the results can be found in ref. 22 .

For the PL measurement, the $325 \mathrm{~nm}$ line from the Kimmon $30 \mathrm{~mW} \mathrm{He}-\mathrm{Cd}$ laser is used as the excitation source. The $500 \mathrm{~mm}$ focal length monochrometer, the photomultiplier (PMT), and the lock-in amplifier are used for the spectrum acquisition. The samples are loaded in the Oxford Instrument $10 \mathrm{~K}$ closed cycle He refrigerator for controlling the sample temperature.

The PAS measurement is carried out with a mono-energetic positron beam having the maximum positron incident energy of $25 \mathrm{keV}$. The annihilation gamma ray energy spectra are detected by a high purity Ge detector system having the energy resolution of $1.3 \mathrm{keV}$ at the $514 \mathrm{keV}$ gamma line. The energy window for the $S$-parameter is $511 \pm 0.76 \mathrm{eV}$, and those for the $W$ parameter are $511 \pm 3.4 \mathrm{eV}$ and $511 \pm 6.8 \mathrm{eV}$.

\section{Results and discussion}

The XRD spectra of all the samples exhibit only the (002) and (004) peaks. The full width at the half maximum (FWHM) of the (002) peak is $0.21-0.25^{\circ}$ for the as-grown samples grown at $300{ }^{\circ} \mathrm{C}$, and improve to $\sim 0.12^{\circ}$ after the $900{ }^{\circ} \mathrm{C}$ annealing.

Fig. 1(a) shows the $10 \mathrm{~K}$ PL spectra of the samples grown at $T_{\text {sub }}=300{ }^{\circ} \mathrm{C}$ without oxygen annealed at different temperatures. The defect emission of the sample annealed at $600{ }^{\circ} \mathrm{C}$ has the peak at $\sim 2.2 \mathrm{eV}$. As the annealing temperature increases, the peak position, intensity, and width of the GL band would be blue-shifted, increased, and narrowed respectively. After
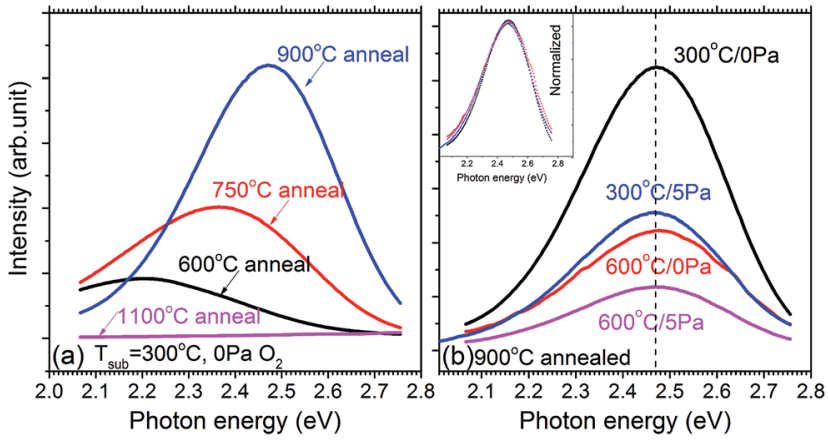

Fig. 1 The low temperature (10 K) PL spectra of (a) the undoped $\mathrm{ZnO}$ samples grown at the substrate temperature of $300^{\circ} \mathrm{C}$ without oxygen subjected to post-growth annealing at different temperatures; and (b) the undoped $\mathrm{ZnO}$ samples grown with the different substrate temperatures $T_{\text {sub }}$ and oxygen pressures $P\left(\mathrm{O}_{2}\right)\left(T_{\text {sub }} / P\left(\mathrm{O}_{2}\right)\right)$ subjected to the post-growth annealing of $900{ }^{\circ} \mathrm{C}$. The insert of (b) shows the normalized spectra in (b). annealing at $900{ }^{\circ} \mathrm{C}$, the peak position is blue-shifted to $2.47 \mathrm{eV}$. For the other samples grown with the different initial conditions, similar thermal evolution in the spectral features is observed, although the exact shape of the GL band depends on the initial growth conditions. The $10 \mathrm{~K}$ PL spectra of the samples grown at different initial growth conditions and annealed at $900{ }^{\circ} \mathrm{C}$ are shown in Fig. 1(b). The corresponding normalized spectra are shown in the insert of Fig. 1(b). It clearly demonstrates that the same GL band peaking at $2.47 \mathrm{eV}$ is yielded after the $900{ }^{\circ} \mathrm{C}$ annealing regardless of the initial growth parameters.

The thermal evolution of the GL in the undoped samples can be understood as follows. The GL's of the samples annealed at temperatures lower than $900{ }^{\circ} \mathrm{C}$ are the superposition of the defect emissions contributed from more than one defect origins. As the samples grown at different conditions and annealed at different temperatures would have different compositions of the involved defects, the shape and the peak position of the resultant GL (which is governed by the relative composition of the different defects ${ }^{20}$ ) is thus dependent on the annealing temperature and the initial growth parameters. However as the annealing temperature increases to $900{ }^{\circ} \mathrm{C}$, all the samples irrespective of the initial growth condition exhibit the GL with the same peak position and shape. The GL bands of all the samples annealed at $900{ }^{\circ} \mathrm{C}$ (peaked at $2.47 \mathrm{eV}$ as seen in Fig. 1(b)) are originated from a single type of defect. The other defects contributed for the GL bands as found in the samples annealed at temperatures lower than $900{ }^{\circ} \mathrm{C}$ are thermally removed. It is also noticed that the $2.47 \mathrm{eV}$ defect emission disappears after the temperature of $1100{ }^{\circ} \mathrm{C}$ (see Fig. 1(a)).

Fig. 2(a) and (b) show the temperature dependent PL spectra of the samples grown at $T_{\text {sub }}=600{ }^{\circ} \mathrm{C}$ and $P\left(\mathrm{O}_{2}\right)=1.3 \mathrm{~Pa}$ annealed at $750{ }^{\circ} \mathrm{C}$ and $900{ }^{\circ} \mathrm{C}$ respectively. For the sample annealed at $750{ }^{\circ} \mathrm{C}$, the peak position of the PL spectra is at $2.31 \mathrm{eV}$ at $10 \mathrm{~K}$. The peak position shifts to higher energy and the intensity decreases with increasing temperature. This could be understood as that the emissions from the different defects have different quenching dependence on the measuring temperature. For the PL spectrum of the sample annealed at $900{ }^{\circ} \mathrm{C}$ which is originated from the single type of defect, the

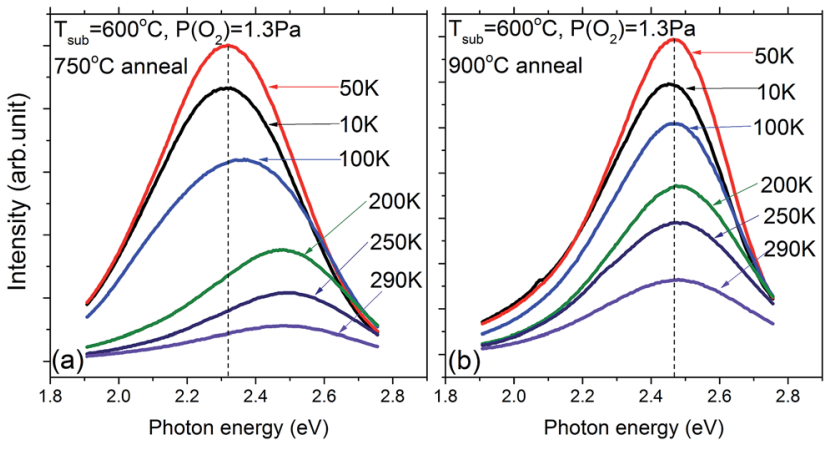

Fig. 2 The temperature dependent PL spectra of the undoped $\mathrm{ZnO}$ samples grown at $T_{\text {sub }}=600{ }^{\circ} \mathrm{C}$ and $P\left(\mathrm{O}_{2}\right)=1.3 \mathrm{~Pa}$ after the postgrowth annealings of (a) $750{ }^{\circ} \mathrm{C}$; and (b) $900{ }^{\circ} \mathrm{C}$. 
peak position does not have significant change and the intensity reduces while the measuring temperature increases as expected. This result is typical for all the sample sets grown with the different initial growth conditions.

Room temperature PAS study is carried out to investigate the origin of the $2.47 \mathrm{eV}$ GL. Zn-vacancy has low formation energy in n-type $\mathrm{ZnO}^{23}$ and is the important acceptor in $\mathrm{ZnO}$ single crystal. ${ }^{24}$ At room temperature, PAS is selectively sensitive to the $\mathrm{Zn}$-vacancy related defects in $\mathrm{ZnO}$. The $S$ and $W$ parameters are used to monitor the Doppler broadening of the line shape of the $511 \mathrm{keV}$ positron-electron annihilation peak. For all the samples, the plots of the $S$-parameter (and also the $W$-parameter) against the positron incident energy $(E)$ show plateaus at $E$ $\sim 5 \mathrm{keV}$, which correspond to the mean positron implantation depth of $\bar{x} \approx 100 \mathrm{~nm}$. While the film thickness is $300 \mathrm{~nm}$, the $S$-parameter (and also the $W$-parameter) of each of the films is taken at $E=5 \mathrm{keV}$.

It is well known that the same single type of Zn-vacancy related defect would present as a straight line in the $S-W$ plot. The $S-W$ parameter plot of the samples grown at the $T_{\text {sub }} / P\left(\mathrm{O}_{2}\right)$ of $300{ }^{\circ} \mathrm{C} / 0 \mathrm{~Pa}, 600{ }^{\circ} \mathrm{C} / 0 \mathrm{~Pa}$, and $600{ }^{\circ} \mathrm{C} / 1.3 \mathrm{~Pa}$ are shown in Fig. 3. The insert shows the zoom-in of the marked region in Fig. 3. The samples that exhibit the GL peaked at $2.47 \mathrm{eV}$ are marked by the green rectangles.

In the previous study on the $\mathrm{ZnO}$ samples grown by the same method, ${ }^{22}$ two kinds $\mathrm{V}_{\mathrm{Zn}}$-related defects (namely $\mathrm{V}_{\mathrm{Zn}-1}$ and $\mathrm{V}_{\mathrm{Zn}-2}$ ) having different microstructures are identified, and their corresponding characteristic straight lines are reproduced in Fig. 3. The intersection of the two straight lines is the $S-W$ value of the $\mathrm{ZnO}$ bulk state. ${ }^{22}$ For the present $300{ }^{\circ} \mathrm{C} / 0$ Pa sample, the $S-W$ data of the as-grown and the samples annealed at $T_{\text {anneal }}<$ $750{ }^{\circ} \mathrm{C}$ lie on the straight line of $\mathrm{V}_{\mathrm{Zn}-1}$, indicating that single type of $\mathrm{V}_{\mathrm{Zn}-1}$ defect exists in these samples. At $T_{\text {anneal }}=900{ }^{\circ} \mathrm{C}$, the

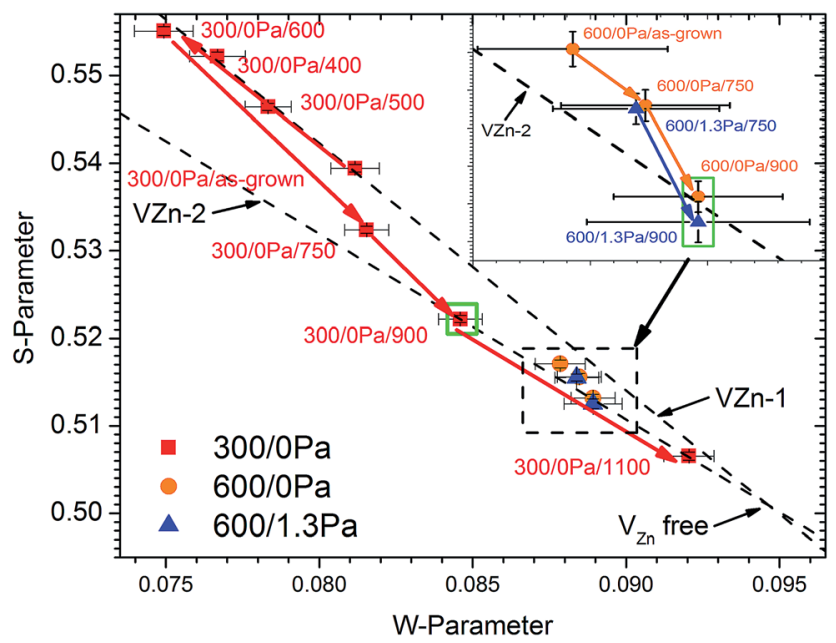

Fig. 3 The $S-W$ plots of the three sets of undoped $\mathrm{ZnO}$ samples fabricated at different $T_{\text {sub }} / P\left(\mathrm{O}_{2}\right)$ of $300{ }^{\circ} \mathrm{C} / 0 \mathrm{~Pa}, 600{ }^{\circ} \mathrm{C} / 0 \mathrm{~Pa}$, and $300{ }^{\circ} \mathrm{C} / 1.3 \mathrm{~Pa}$ subjected to post-growth annealing at different temperatures. The zoom-in of the dash-lined enclosed region is shown in the insert. The arrows indicate the thermal induced conversions to the $V_{Z n-2}$ defect. The samples exhibiting the $G L$ with the peak at $2.47 \mathrm{eV}$ are marked by the green rectangles.
$\mathrm{V}_{\mathrm{Zn}}$ structure transits to the $\mathrm{V}_{\mathrm{Zn}-2}$ structure. Similar transition to the $\mathrm{V}_{\mathrm{Zn}-2}$ structure is also observed in the $600{ }^{\circ} \mathrm{C} / 0 \mathrm{~Pa}$, and $600{ }^{\circ} \mathrm{C} / 1.3 \mathrm{~Pa}$ samples after the $900{ }^{\circ} \mathrm{C}$ annealing (insert of Fig. 3). To conclude the PAS story, the transition to the $\mathrm{Zn}$ vacancy microstructure of $\mathrm{V}_{\mathrm{Zn}-2}$ occurs at $900{ }^{\circ} \mathrm{C}$ in all the samples, which exactly coincides with the introduction of the $2.47 \mathrm{eV}$ GL. The GL peaked at $2.47 \mathrm{eV}$ observed after the annealing of $900{ }^{\circ} \mathrm{C}$ is thus associated to the $\mathrm{Zn}$-vacancy related defect $\mathrm{V}_{\mathrm{Zn}-2}$. From Fig. 3, the $S$-parameter of the sample grown at $300{ }^{\circ} \mathrm{C} / 0$ Pa decreases (and thus so does the concentration of $\mathrm{V}_{\mathrm{Zn}-2}$ ) after the annealing of $1100{ }^{\circ} \mathrm{C}$. This is consistent with the observation that the GL having the $2.47 \mathrm{eV}$ peak anneals out after the annealing of $1100{ }^{\circ} \mathrm{C}$ is performed (as shown in Fig. 1(a)).

The low temperature $(10 \mathrm{~K})$ near band edge PL spectra of the $600{ }^{\circ} \mathrm{C} / 1.3 \mathrm{~Pa}$ samples annealed at different temperatures are shown in the insert of Fig. 4 . The $3.356 \mathrm{eV}$ line observed in the as-grown sample is assigned to the neutral donor bound exciton $\left(\mathrm{D}^{0} \mathrm{X}\right)$ emission. ${ }^{25}$ Its first and second LO-phonon replicas are also observed. The peak positions of the $\mathrm{D}^{0} \mathrm{X}, 1 \mathrm{LO}\left(\mathrm{D}^{0} \mathrm{X}\right)$ and $2 \mathrm{LO}\left(\mathrm{D}^{0} \mathrm{X}\right)$ are shown in Fig. 5 , showing that their peak positions are red-shifted with the increasing temperature.

The low temperature $(10 \mathrm{~K})$ near band edge PL spectrum of the $600{ }^{\circ} \mathrm{C} / 1.3 \mathrm{~Pa}$ sample annealed at $900{ }^{\circ} \mathrm{C}$ is shown in the insert of Fig. 4, and the corresponding temperature dependent PL spectra with the PL intensity plotted in log scale are shown in Fig. 4. The $\mathrm{D}^{0} \mathrm{X}$ (and its two-electron satellite (TES) ${ }^{26}$ ) emissions persist after the sample is annealed at $900{ }^{\circ} \mathrm{C}$. As the measuring temperature increases, the $\mathrm{D}^{0} \mathrm{X}$ and TES peaks red-shift with their intensity decreased, and they merge at $80 \mathrm{~K}$ (Fig. 4). A peak of $3.229 \mathrm{eV}$ is found in the low temperature PL spectrum of this sample (Fig. 4). This peak cannot be the first and second phonon replicas of the $\mathrm{D}^{0} \mathrm{X}$ observed in the as-grown sample as it exhibits blue-shift with increasing temperature (Fig. 4 and 5). One of the possible origins of this $3.229 \mathrm{eV}$ peak is associated

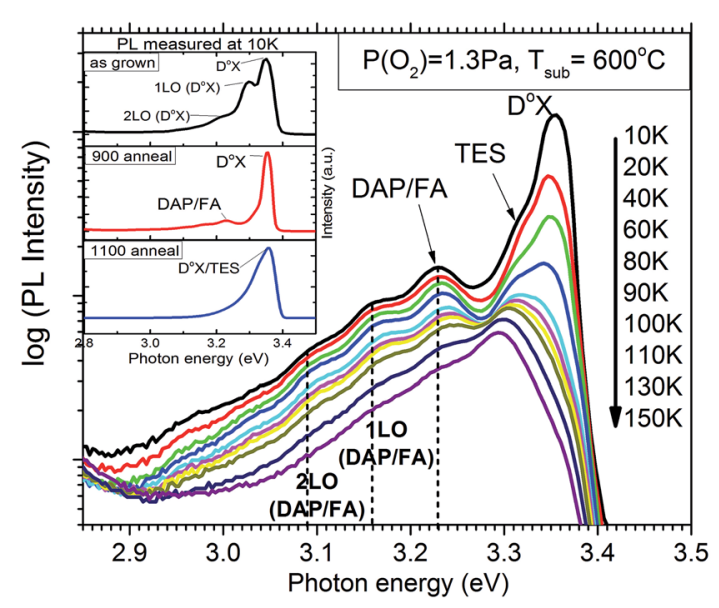

Fig. 4 The temperature dependent NBE PL spectra of the undoped ZnO sample grown at $T_{\text {sub }}=600{ }^{\circ} \mathrm{C}$ and $P\left(\mathrm{O}_{2}\right)=1.3 \mathrm{~Pa}$ after the $900{ }^{\circ} \mathrm{C}$ post-growth annealing. The $\mathrm{PL}$ intensity is plotted with the log scale. The insert shows the low temperature $(10 \mathrm{~K})$ near band edge $\mathrm{PL}$ spectra of the as-grown sample, the samples annealed at $900{ }^{\circ} \mathrm{C}$ and $1100{ }^{\circ} \mathrm{C}$ with the $\mathrm{PL}$ intensity in normal scale. 


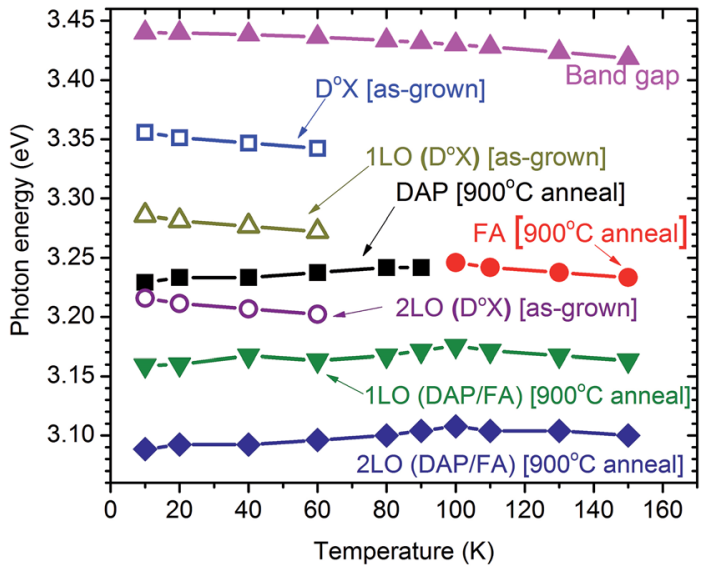

Fig. 5 The peak positions of some NBE emissions versus the measuring temperature. The samples are grown at $T_{\text {sub }}=600{ }^{\circ} \mathrm{C}$ and $P\left(\mathrm{O}_{2}\right)=1.3 \mathrm{~Pa}$. These peaks include the $\mathrm{D}^{0} \mathrm{X}$ and its first two LO replicas identified in the as-grown sample, as well as the DAP/FA emissions and its two LO replicas identified in the sample annealed at $900{ }^{\circ} \mathrm{C}$. The band gap calculated by the Varshni equation is also included for reference.

with the free exciton (FX) emission of $\sim 3.37 \mathrm{eV}$, which has been observed in the low temperature PL spectra of $\mathrm{ZnO}^{27,28}$ Its second LO-phonon replica (2LO (FX)) would overlap with this $3.229 \mathrm{eV}$ peak, and the observed blue-shift could be due to the transition from the $\mathrm{D}^{0} \mathrm{X}$ emission to the $\mathrm{FX}$ emission as the temperature increases. Another possible origin of the $3.229 \mathrm{eV}$ emission is the donor-acceptor-pair (DAP) transition. The blue shift is due to the enhancement of the free-electron-to-acceptor (FA) emission because of the shallow donor ionization as the measuring temperature increases.

Teke $e$ t $a l .{ }^{28}$ have studied the excitonic fine structure of high quality wurtzite structure $\mathrm{ZnO}$ single crystal produced by Cermet Inc. The intrinsic excitonic features are significantly strengthened with the forming gas annealing due to the improvement of the crystal quality of the surface. Phonon replicas 1LO (FX), 2LO (FX), and 3LO (FX) are observed in the post-growth forming gas annealed sample. The $3 \mathrm{LO}$ (FX) are very weak and barely detectable. In the present study, higher order LO-phonon replicas of the $3.229 \mathrm{eV}$ are also observed at $3.163 \mathrm{eV}$ and $3.093 \mathrm{eV}$ in the low temperature (10 K) PL of Fig. 4. If the $3.229 \mathrm{eV}$ peak is associated with the $2 \mathrm{LO}$ of the FX emission, then the $3.163 \mathrm{eV}$ and $3.093 \mathrm{eV}$ would be the $3 \mathrm{LO}$ (FX) and $4 \mathrm{LO}$ (FX) respectively. The peak positions of these two phonon replicas are also observed to be blue-shifted by the increasing temperature (see Fig. 5). Though not specified in Teke et al. ${ }^{28}$ the high crystalline quality $\mathrm{ZnO}$ single crystal produced by Cermet has typical electron mobility of larger than $200 \mathrm{~cm}^{2} \mathrm{~V}^{-1} \mathrm{~s}^{-1}$. For the present PLD grown samples annealed at $900{ }^{\circ} \mathrm{C}$, the electron mobility is $50-95 \mathrm{~cm}^{2} \mathrm{~V}^{-1} \mathrm{~s}^{-1}$ depending on the initial growth oxygen pressure. ${ }^{22}$ The observation of the $4 \mathrm{LO}$ (FX) in the PLD grown film (expected to have inferior crystalline quality than the single crystal in Teke et $a .^{28}$ ) is thus less likely tenable. Moreover if the $3.229 \mathrm{eV}$ in the $10 \mathrm{~K} \mathrm{PL}$ spectrum is the $2 \mathrm{LO}(\mathrm{FX})$, the corresponding stronger $1 \mathrm{LO}(\mathrm{FX})$ is expected to be presence at $\sim 3.299 \mathrm{eV}$ in the same spectrum. However such peak cannot be found. The $3.229 \mathrm{eV}$ in the low temperature PL spectrum is thus plausibly assigned to the DAP/ FA emission, while the $3.163 \mathrm{eV}$ and $3.093 \mathrm{eV}$ are the corresponding 1LO (DAP/FA) and 2LO (DAP/FA).

The peak position of the DAP/FA as a function of the measuring temperature is shown in Fig. 5. The band gap calculated by the Varshni equation is also included. As the temperature increases, the DAP/FA peak increases from $3.229 \mathrm{eV}$ at $10 \mathrm{~K}$ to the maximum of $3.246 \mathrm{eV}$ at $100 \mathrm{~K}$ and then decreases. The increase of the photon energy with increasing temperature at temperature below $100 \mathrm{~K}$ is associated with the enhancement of the FA emission induced by the shallow donor ionization. At temperatures higher than $100 \mathrm{~K}$, the red-shift of the peak is related to the increase of the band gap and thus the decrease of the photon energy. The relations between the donor level $E_{\mathrm{D}}$, acceptor level $E_{\mathrm{A}}$, the photons energies of the FA $\left(E_{\mathrm{FA}}\right)$ and DAP $\left(E_{\mathrm{DAP}}\right)$ emissions are given by: $:^{21}$

$$
\begin{gathered}
E_{\mathrm{D}}=\left[E_{\mathrm{FA}}(T)-k_{\mathrm{B}} T / 2\right]-\left[E_{\mathrm{DAP}}(T)-\alpha N_{\mathrm{D}}{ }^{1 / 3}\right] \\
E_{\mathrm{A}}=\left[E_{\mathrm{g}}(T)-E_{\mathrm{D}}\right]-\left[E_{\mathrm{DAP}}(T)-\alpha N_{\mathrm{D}}{ }^{1 / 3}\right]
\end{gathered}
$$

where $N_{\mathrm{D}}^{1 / 3}$ is the average distance between the donors, and

$$
\alpha=\left(\frac{4 \pi}{3}\right)^{1 / 3} \frac{e^{2}}{4 \pi \varepsilon_{0} \varepsilon}=2.7 \times 10^{-8} \mathrm{eV} \mathrm{cm}
$$

To calculate the acceptor level $E_{\mathrm{A}}, E_{\mathrm{D}}$ in eqn (1) is substituted into eqn (2) and the term $E_{\mathrm{DAP}}(T)-\alpha N_{\mathrm{D}}{ }^{1 / 3}$ is found to be cancelled, which yields:

$$
E_{\mathrm{A}}=E_{\mathrm{g}}(T)-E_{\mathrm{FA}}(T)+k_{\mathrm{B}} T / 2
$$

Taking the approximation that the transition is pure FA at the high temperature (say $100 \mathrm{~K}$, i.e. $\left.E_{\mathrm{FA}}(100 \mathrm{~K})=3.246 \mathrm{eV}\right), E_{\mathrm{A}}$ can be calculated to be $188 \pm 9 \mathrm{meV}$ from eqn (3) with the $E_{\mathrm{g}}(100$ K) obtained through the Varshni equation.

At the temperature of $1100{ }^{\circ} \mathrm{C}$ annealing, the $\mathrm{D}^{0} \mathrm{X} / \mathrm{TES}$ merged peak becomes broadened (insert of Fig. 4) and it is difficult to determine unambiguously whether the DAP/FA peak exists. However by monitoring the first and the second phonon replicas of the DAP/FA in the log scaled PL spectra, they do not exist in the PL spectrum of the samples annealed at $1100{ }^{\circ} \mathrm{C}$.

Thonke et al. ${ }^{21}$ observed the DAP emission $(3.220 \mathrm{eV})$ in the PL spectrum of $\mathrm{ZnO}$ measured at $5 \mathrm{~K}$, and the FA emission $(3.236 \mathrm{eV})$ emerged at the temperature of $40 \mathrm{~K}$. The corresponding acceptor was found to have $E_{\mathrm{A}}=195 \pm 10 \mathrm{meV}$, which is similar to the $E_{\mathrm{A}}$ found in the present study. While considering the possible candidate for the acceptor, the $E_{\mathrm{A}}$ value was compared with the theoretical values available at that time. Thonke $e t a l .{ }^{21}$ ruled out the possibility of assigning the acceptor to Zn-vacancy as Zn-vacancy was taken as the singly ionized acceptor with $E_{\mathrm{A}} \sim 0.8 \mathrm{eV} .{ }^{21}$ The acceptor was assigned to $\mathrm{N}_{\mathrm{O}}$ as its theoretical $E_{\mathrm{A}}$ was $\sim 200 \mathrm{meV}$, though the details of the calculation was not given. Based on the density functional theory (DFT) with the local density approximation (LDA) or 
generalized gradient approximation (GGA), the theoretical $E_{\mathrm{A}}$ value of $\mathrm{N}_{\mathrm{O}}$ was $\sim 0.4 \mathrm{eV} \cdot{ }^{29,30}$ However, DFT-LDA (GGA) calculations usually severely underestimate the band gap, and thus lead to large uncertainty in the defect ionization level for wide band gap materials. Lyons et $a l^{31}$ has recently performed the advanced first principle study on $\mathrm{N}_{\mathrm{O}}$ using the hybrid functionals, which could give a good description to the band gap. The $\mathrm{N}_{\mathrm{O}}$ was found to be a deep acceptor having the ionization energy of $1.3 \mathrm{eV}$. Moreover, advanced first principal calculation showed that the Zn-vacancy is doubly ionized acceptor having transition levels of $\varepsilon(0 /-)=0.18 \mathrm{eV}$ and $\varepsilon(-/ 2-)=0.87 \mathrm{eV} \cdot{ }^{23}$ The acceptor involved in the DAP/FA emission is thus not likely associated to the $\mathrm{N}_{\mathrm{O}}$ acceptor.

With first principle calculation, Janotti and Van de Walle ${ }^{23}$ report the transition levels of $\varepsilon(0 /-)=0.18 \mathrm{eV}$ and $\varepsilon(-/ 2-)=$ $0.87 \mathrm{eV}$ for the Zn-vacancy in ZnO. Concerning the GL, the photon energy of $2.47 \mathrm{eV}$ could be associated with the conduction band to acceptor transition with the acceptor level at $0.93 \mathrm{eV}$, which is close to the calculated $(-/ 2-)$ level for the Zn-vacancy. For the DAP/FA emission at $3.229 \mathrm{eV}$, it is associated with the acceptor with the $E_{\mathrm{A}}$ of $0.19 \mathrm{eV}$, which agrees well with the calculated (0/-) level for the Zn-vacancy. The assignment of the GL with peak at $2.47 \mathrm{eV}$ to $\mathrm{Zn}$-vacancy related defect is also confirmed by the result of PAS, which is selectively sensitive to Zn-vacancy in ZnO. Concerning the annealing behaviors, both the GL and the DAP/FA are induced after the annealing of $900{ }^{\circ} \mathrm{C}$. Thus based on the results of PAS, the annealing behaviors, and the comparison with the theoretical study, the GL with the peak at $2.47 \mathrm{eV}$ is associated with the $(-/ 2-)$ state of Zn-vacancy. The DAP/FA emission of $3.229 \mathrm{eV}$ observed in the $10 \mathrm{~K} \mathrm{PL}$ spectrum is associated with the $(0 /-)$ acceptor level of Zn-vacancy.

\section{Conclusion}

In conclusion, the GL with peak at $2.47 \mathrm{eV}$ and the DAP/FA emission are induced in the $10 \mathrm{~K} \mathrm{PL}$ spectra after the $\mathrm{ZnO}$ samples are annealed at $900{ }^{\circ} \mathrm{C}$ regardless of the initial growth condition. Supported by the correlated annealing behavior of the $\mathrm{V}_{\mathrm{Zn}}$-related defect as revealed by PAS, and the compatibility with the transition levels of $\mathrm{V}_{\mathrm{Zn}}$ obtained through first principle calculation, the GL and the DAP/FA emissions observed in the present PLD grown ZnO samples have the same origin of the $\mathrm{Zn}$ vacancy defect.

\section{Acknowledgements}

This work is supported by the HKSAR RGC under the GRF scheme with the project no. of 7036/12P. We would like to thank for Mr X. H. Wang and Prof. S. J. Xu with their involvement in the PL measurement and their expertise offered.

\section{References}

1 Ü. Özgür, Y. I. Alivov, C. Liu, A. Teke, M. A. Reshchikov, S. Doğan, V. Avrutin, S.-J. Cho and H. Morkoç, J. Appl. Phys., 2005, 98, 041301.
2 M. D. McCluskey and S. J. Jokela, J. Appl. Phys., 2009, 106, 071101.

3 S. C. Su, H. Zhu, L. X. Zhang, M. He, L. Z. Zhao, M. He, L. Z. Zhao, S. F. Yu, J. N. Wang and F. C. C. Ling, Appl. Phys. Lett., 2013, 103, 131104.

4 Z. K. Tang, G. K. L. Wong, P. Yu, M. Kawasaki, A. Ohtomo, H. Koinuma and Y. Segawa, Appl. Phys. Lett., 1998, 72, 3270.

5 J. S. Liu, C. X. Shan, H. Shen, B. H. Li, Z. Z. Zhang, L. Liu, L. G. Zhang and D. Z. Shen, Appl. Phys. Lett., 2012, 101, 011106.

6 A. Tsukazaki, A. Ohotomo, T. Onuma, M. Ohtani, T. Makino, M. Sumiya, K. Ohtani, S. F. Chichibu, S. Fuke, Y. Segawa, H. Ohno, H. Koinuma and M. Kawasaki, Nat. Mater., 2005, 4, 42.

7 H. Zhu, C. X. Shan, B. Yao, B. H. Li, J. Y. Zhang, Z. Z. Zhang, D. X. Zhao, D. S. Shen, X. W. Fan, Y. M. Liu and Z. K. Tang, Adv. Mater., 2009, 21, 1613.

8 Y. J. Lu, C. X. Shan, M. M. Jiang, B. H. Li, K. W. Liu, R. G. Li and D. Z. Shen, RSC Adv., 2014, 4, 16578.

9 R. Dingle, Phys. Rev. Lett., 1969, 23, 579.

10 Y. W. Heo, D. P. Norton and S. J. Peaton, J. Appl. Phys., 2005, 98, 073502.

11 X. Yang, G. Du, X. Wang, J. Wang, B. Liu, Y. Zhang, D. Liu, D. Liu, H. C. Ong and S. Yang, J. Cryst. Growth, 2003, 252, 275.

12 B. Guo, Z. R. Qiu and K. S. Wong, Appl. Phys. Lett., 2003, 82, 2290.

13 H.-J. Egelhaaf and D. Oelkrug, J. Cryst. Growth, 1996, 161, 190.

14 K. Vanheusden, C. H. Seager, W. L. Warren, D. R. Tallant and J. A. Voigt, Appl. Phys. Lett., 1996, 68, 403.

15 S. A. Studenikin, N. Golego and M. Cocivera, J. Appl. Phys., 1998, 84, 2287.

16 F. H. Leiter, H. R. Alves, N. G. Romanov, D. V. Hoffmann and B. K. Meyer, Phys. B, 2003, 340-342, 201.

17 N. O. Korsunska, L. V. Borkovska, B. M. Bulakh, L. Y. Khomenkova, V. I. Kushnirenko and I. V. Markevich, J. Lumin., 2003, 102-103, 733.

18 B. Lin, Z. Fu and Y. Jia, Appl. Phys. Lett., 2001, 79, 943.

19 C. Ton-That, L. Weston and M. R. Phillips, Phys. Rev. B: Condens. Matter Mater. Phys., 2012, 86, 115205.

20 J. P. Lv and C. D. Li, Appl. Phys. Lett., 2013, 103, 232114.

21 K. Thonke, T. Gruber, N. Trofilov, R. Schönfelder, A. Waag and R. Sauer, Phys. B, 2001, 308-310, 945.

22 Z. Wang, S. Su, F. Chi-Chung Ling, W. Anwand and A. Wagner, J. Appl. Phys., 2014, 116, 033508.

23 A. Janotti and C. Van de Walle, Phys. Rev. B: Condens. Matter Mater. Phys., 2007, 76, 165202.

24 F. Tuomisto, V. Ranki, K. Saarinen and D. C. Look, Phys. Rev. Lett., 2003, 91, 205502.

25 B. K. Meyer, H. Alves, D. M. Hofmann, W. Kriegseis, D. Forster, F. Bertram, J. Christen, A. Hoffmann, M. Straßburg, M. Dworzak, U. Haboeck and A. V. Rodina, Phys. Status Solidi A, 2004, 241, 231.

26 M. R. Wagner, G. Callsen, J. S. Reparaz, J.-H. Schulze, R. Kirste, M. Cobet, I. A. Ostapenko, S. Rodt, C. Nenstiel, M. Kaiser, A. Hoffmann, A. V. Rodina, M. R. Phillips, 
S. Lautenschläger, S. Eisermann and B. K. Meyer, Phys. Rev. B: Condens. Matter Mater. Phys., 2011, 84, 035313.

27 D. C. Reynolds, D. C. Look, B. Jogai, C. W. Litton, G. Cantwell and W. C. Harsch, Phys. Rev. B: Condens. Matter Mater. Phys., 1999, 60, 2340.

28 A. Teke, Ü. Özgür, S. Doğan, X. Gu, H. Morkoç, B. Nemeth, J. Nause and H. O. Everitt, Phys. Rev. B: Condens. Matter Mater. Phys., 2004, 70, 195207.
29 C. H. Park, S. B. Zhang and S.-H. Wei, Phys. Rev. B: Condens. Matter Mater. Phys., 2002, 66, 073202.

30 E.-C. Lee, Y.-S. Kim, Y.-G. Jin and K. J. Chang, Phys. Rev. B: Condens. Matter Mater. Phys., 2001, 64, 085120.

31 J. L. Lyons, A. Janotti and C. G. Van de Walle, Appl. Phys. Lett., 2009, 95, 252105.

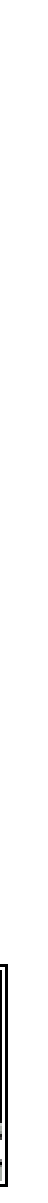

